\title{
Phosphonic acid appended naphthalenediimide molecular receptor for saccharides and aminoglycoside antibiotics recognition
}

\author{
Kamalakar P. Nandre ${ }^{a}$, Sidhanath V. Bhosale ${ }^{a, b *}$ \\ apolymers and Functional Materials Division, CSIR-Indian Institute of Chemical Technology, \\ Hyderabad-500 007, Telangana, India. \\ ${ }^{\mathrm{b}}$ Academy of Scientific and Innovative Research (AcSIR), Ghaziabad-201002, India. \\ Corresponding author E-mail: bhosale@iict.res.in
}

\begin{abstract}
Design of symmetric phosphonic acid functionalized naphthalene diimide bolaamphiphile (NDI 1) is reported. NDI 1 based molecular recognition of saccharides and aminoglycoside antibiotics in aqueous media was investigated. UV-vis and fluorescence measurements revealed an efficient protocol for NDI 1 as molecular receptor. The sensor successfully recognises saccharides and aminoglycoside antibiotics kanamycin and neomycin in terms of both absorbance intensity and binding affinity. This protocol provides new platform for the design and synthesis of phosphonic acid appended NDI sensor for recognition of multifunctional biomolecules.
\end{abstract}

Keywords: aminoglycoside antibiotics; bolaamphiphile; molecular recognition; saccharides; naphthalene diimide

\section{Introduction}

Biologically important molecular system such as carbohydrates or saccharides plays a significant role in the metabolic pathways of living systems [1-3]. Carbohydrates are placed on the cell surface to act as sensors and as biochemical signals [4a] The structural diversity of the carbohydrates on the level of complexity far exceeds those of nucleic acids and proteins. Carbohydrates or saccharides are the chemical storage in the plant and is the source as a for 
human body. Among the carbohydrates, monosaccharides possesses several stereocentres around each carbon atom creating individual stereoisomers with unique chemical and physical characteristics and are biologically important. In recent years, recognition of carbohydrates by synthetic molecular architecture has gained momentum. In the metabolic pathways of living systems, saccharides playa a key role. Therefore detecting of the biologically important saccharide presence and their concentration in aqueous media is essential in industrial and also medicinal fields $[4 b, c]$. Various synthetic receptors for saccharide detection (galactose, glucose, fructose, ribose, and xylose) [13-15] was used various techniques such as electrochemical [8], colorimetric [10], UV-vis [6], fluorescence emission [5], circular dichroism [7], polymeric [9], surface functionalised sensor [11], and also photoinduced electron transfer [12]. But these methods display some serious drawback in aqueous media. The recognition of saccharides by small molecular receptor based on boronic acid show tremendous growth during the last decade [16]. The molecular architecture with boronic functional group form complexes with saccharides through covalent interaction and represent an important binding force in the detection of saccharides [17]. Recently, the design, synthesis and application of novel chromophores with different functional groups [16-19] for the recognition of saccharides and aminoglycoside antibiotics [22] in aqueous media has gained great importance.

In aqueous media recognition of saccharides and aminoglycoside antibiotics remains an important challenge due to competitive hydrogen bonding by a solvent [23] Literature search revealed that, to date very less examples of saccharide recognition based on phosphonic acid functionalized chromophores are reported [24-26]. It is well documented that $\mathrm{P}=\mathrm{O}$ functional groups are strong hydrogen bond acceptor and plays a key role in saccharide recognition [2728]. Rao et al. reported the complex formation between phosphate and phosphonate with 1,2diols in solid state [29]. The binding of fructose to DNA via phosphonate and 1,2-diol 
interaction was proposed by Pelmore and co-workers [30]. Molecular receptor based on phosphonic acid functionalised naphthalene diimide for saccharide and aminoglycoside antibiotics are not reported till date [31]. With the aid of better chromophore with hydrogen bonding phosphonic acid functional group, it will possible to develop sensitive sensors to detect saccharides and aminoglycoside antibiotics in aqueous media. Herein, we report design of symmetric bolaamphiphile NDI $\mathbf{1}$ as a molecular receptor towards saccharides and aminoglycoside antibiotics. The NDI 1 bolaamphiphile shows complex formation with monosaccharides and aminoglycosides via non-covalent H-bonding interactions. In hydrophilic environment NDI 1 exhibits intermolecular $\pi$ - $\pi$ stacking interactions, which lead to change in UV-vis absorption and fluorescence emission spectral peak intensities.

\section{Experimental Section}

A stock solution of bolaamphiphile NDI $1(2.0 \mathrm{mM})$ was prepared in $\mathrm{H}_{2} \mathrm{O}$ and $20 \mu \mathrm{L}$ stock solution added to a quartz cuvette and further diluted in $2 \mathrm{~mL} \mathrm{H}_{2} \mathrm{O}$ (path length $=1 \mathrm{~cm}$ ) then $\mathrm{UV}$-vis absorption and fluorescence emission was measured by manipulating $\mathrm{pH}$ by using either $0.1 \mathrm{~N} \mathrm{HCl}$ ) or $\mathrm{NaOH}$, respectively. The receptor then further titrated with various saccharides and aminoglycoside antibiotics $\left(1 \times 10^{-2} \mathrm{M}\right)$.

\subsection{UV-vis measurements}

The UV-vis absorption spectra were recorded using a Shimadzu spectrophotometer (model: UV 1800) at r.t. in the quartz cell with $1.0 \mathrm{~cm}$ path length. Furthermore, the spectra's NDI 1 were recorded in $\mathrm{H}_{2} \mathrm{O}$ with saccharides, kanamycin and neomycin at $\mathrm{pH} 9.0$.

\subsection{Fluorescence measurements}

The fluorescence (FL) was recorded using Schimadzu Fluorescence Spectrophotometer. (model: RF-6000) in $\mathrm{H}_{2} \mathrm{O}$ at $\mathrm{pH} 9$ at room temperature with excitation wavelength $\left(\lambda_{\mathrm{ex}}=384\right.$ $\mathrm{nm})$.

\section{Result and discussion}


In aqueous media the molecular recognition of carbohydrates and aminoglycoside antibiotics leads to give important information. The interaction between NDI 1 bolaamphiphile with water soluble phosphonic acid head groups offer an important platform for recognition of saccharides and aminoglycoside antibiotics. The recognition study was performed at $\mathrm{pH} 9$, since phosphonic functional group completely deprotonated at this state. The deprotonated phosphonic acid able to interact with carbohydrates and aminoglycoside antibiotics via noncovalent H-bonding. Herein, we investigated the molecular recognition characteristics of the bolaamphiphile NDI 1 against the various monosaccharides such as D- form of galactose, glucose, fructose, lyxose, ribose, xylose as well as aminoglycosides antibiotics (kanamycin and neomycin) as illustrated in Fig. 1. The molecular recognition properties were examined using UV-visible and fluorescence emission spectroscopic techniques.

a)

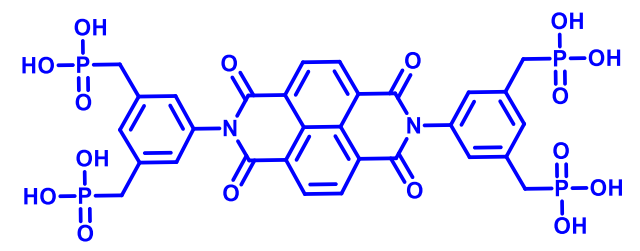

NDI 1 bolaamphiphile

b)

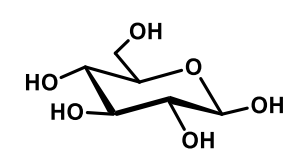

D-Glucose

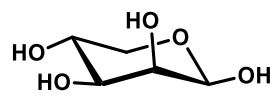

D-Lylose

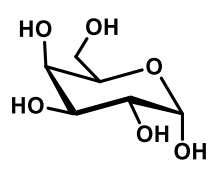

D-Galactose

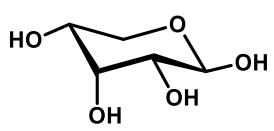

D-Ribose
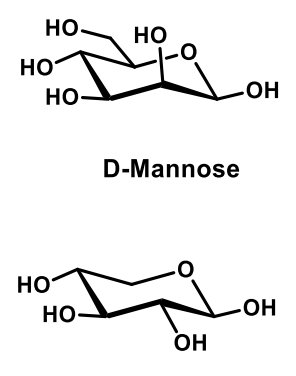

D-Xylose

c)

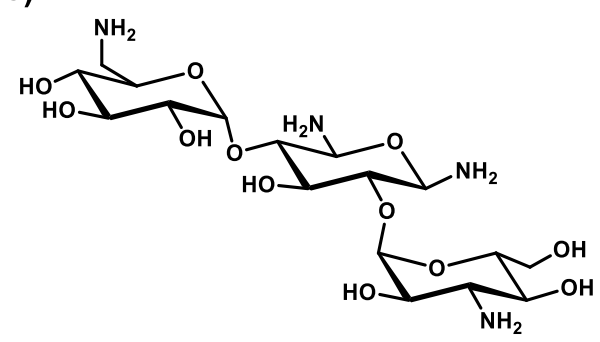

Kanamycin

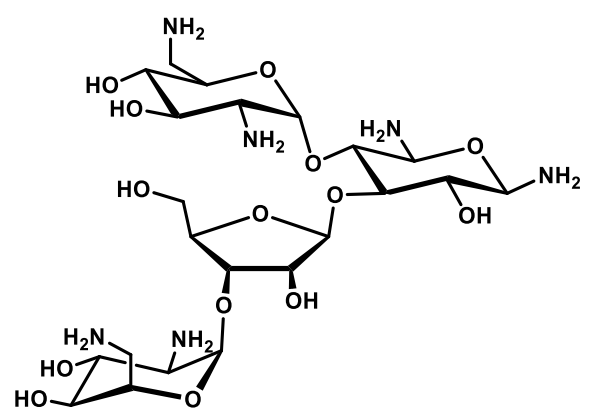

Neomycin B 
Fig. 1 Molecular structures used in this study: (a) NDI 1, (b) monosaccharides and (c) aminoglycosides antibiotics.

\section{1. $U V$-Visible spectroscopy}

The UV-vis spectroscopic measurements of NDI 1 bolaamphiphile was performed in aqueous media at $\mathrm{pH}$ 9. At room temperature, NDI 1 bolaamphiphile $\left(1 \times 10^{-5} \mathrm{M}\right)$ exhibits strong two absorption maxima one at $363 \mathrm{~nm}$ and second one at $384 \mathrm{~nm}$ with small peak at $347 \mathrm{~nm}$ which attributed to $\pi-\pi *$ transition [32]. The titration experiments of NDI 1 with carbohydrates such as D- form of galactose, glucose, fructose, lyxose, ribose, and xylose and also aminoglycoside antibiotics e.g. kanamycin and neomycin in aqueous media. The concentration of the saccharide is $1 \times 10^{-2} \mathrm{M}$. As illustrated in Fig. 2a, upon addition of D-galactose, peak intensity of the absorption maxima at $363 \mathrm{~nm}$ and $384 \mathrm{~nm}$ decreases and stabilized with the addition of 20 equiv. of the D-galactose. Furthermore, the addition of other carbohydrate as well as aminoglycoside moieties display the same trend with respective change in absorption at 363 nm and $384 \mathrm{~nm}$ (Fig. 2b-f). The changes of the bolaamphiphile NDI 1 complexes with these sugars via non-covalent H-bonding interactions and in water media NDI 1 undertakes strong $\pi-\pi$ intermolecular interactions which lead to change in absorption peak intensities. 

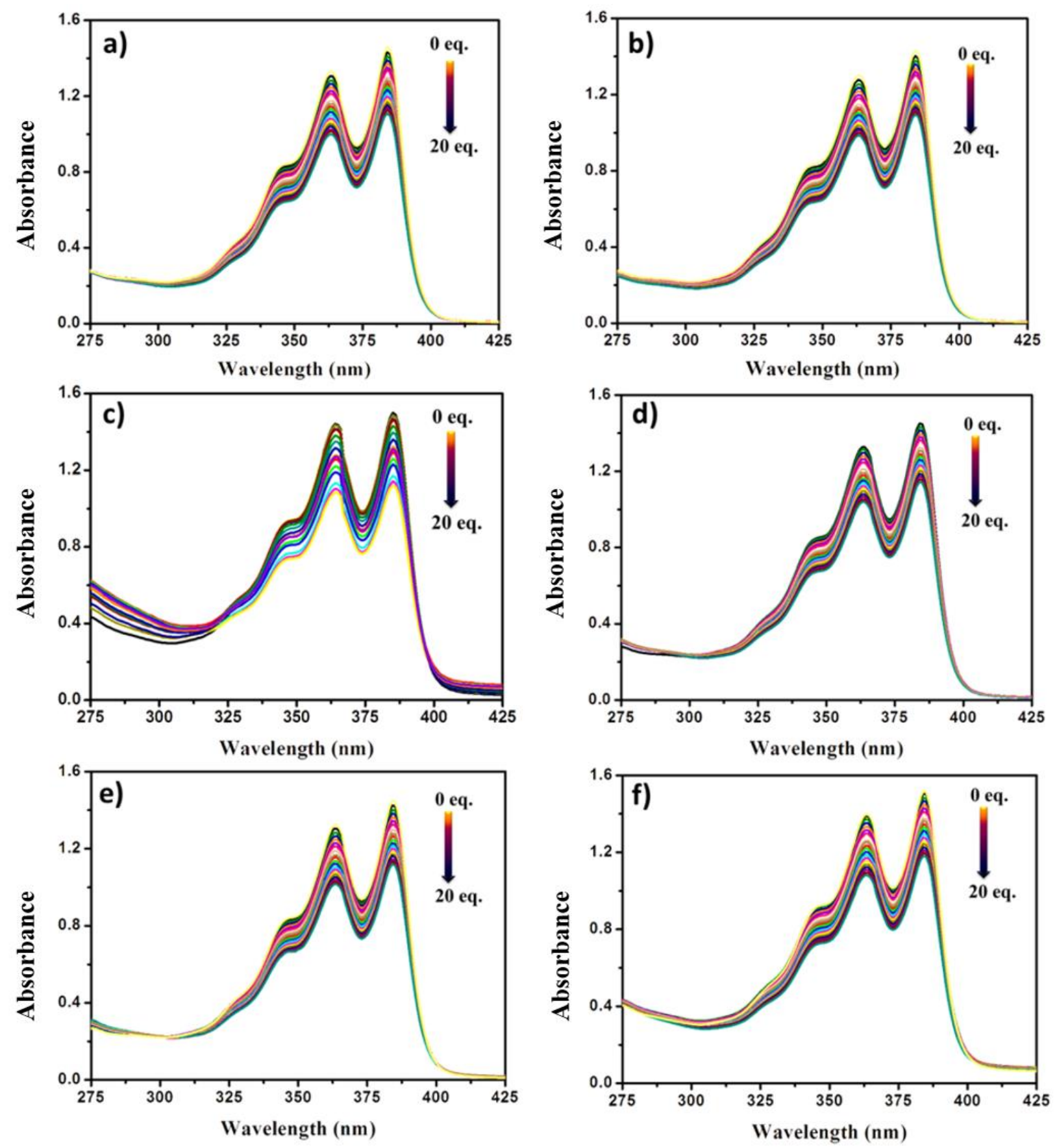

Fig. 2 UV-visible absorption spectra of bolaamphiphile NDI $1\left(1 \times 10^{-5} \mathrm{M}\right)$ at $\mathrm{pH} 9$ in $\mathrm{H}_{2} \mathrm{O}$ upon incremental addition of $\mathrm{D}$ - form of sugars $\left(1 \times 10^{-2} \mathrm{M}\right)$ as: a) galactose, b) glucose, c) mannose, d) lyxose, e) ribose and f) xylose 

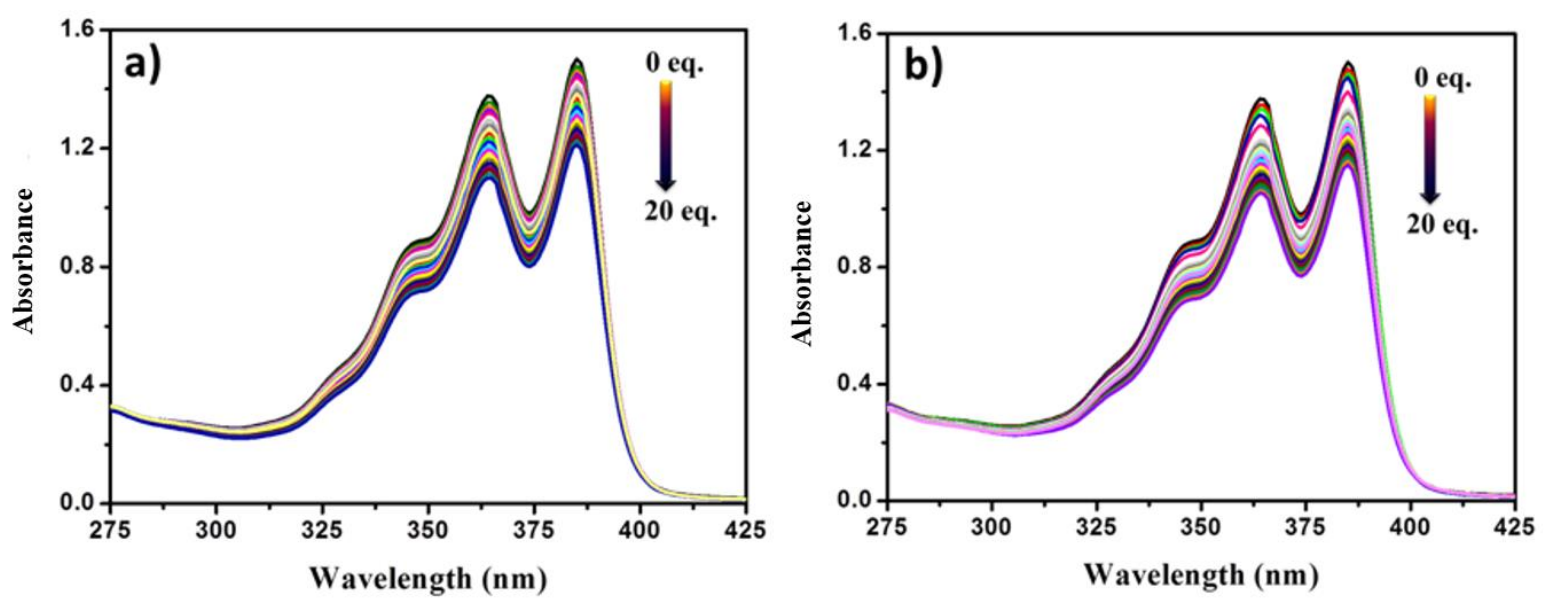

Fig. 3 UV-visible spectrums of NDI $1\left(1 \times 10^{-5} \mathrm{M}\right)$ in $\mathrm{H}_{2} \mathrm{O}$ at $\mathrm{pH} 9$ upon addition of a) kanamycin (0-20 equiv., $\left.1 \times 10^{-2} \mathrm{M}\right)$, b) neomycin (0-20 equiv., $\left.1 \times 10^{-2} \mathrm{M}\right)$.

To generalise the recognition ability of NDI 1 bolaamphiphile, we further examined the UVvia absorption changes upon addition of kanamycin (0-20 equiv.) and neomycin (0-20 equiv.) at $\mathrm{pH}$ 9. The absorption maxima at $363 \mathrm{~nm}$ and $384 \mathrm{~nm}$ of NDI 1 with the addition of kanamycin and neomycin display the decrease in intensity as illustrated in Fig. 3a and 3b, respectively. We presume that the deprotonated phosphonic head group may interact with $\mathrm{OH}$ and $-\mathrm{NH}_{2}$ functional groups via non-covalent hydrogen bonding present in kanamycin and neomycin. Thus, UV-vis absorption study indicates the presence of phosphonic head group lead to recognise these carbohydrates and aminoglycosides. Furthermore, we employed UVvis absorption experiments to determine the binding (association) constant of NDI 1 towards these sugars and aminoglycosides

The binding constant $\left(\mathrm{K}_{\mathrm{a}}\right)$ of the bolaamphiphile NDI 1 with the examined carbohydrates and aminoglycoside antibiotics were calculated using UV-vis measurements. As illustrated in Fig. 4a-h, the plot between $1 /(\mathrm{A} 0-\mathrm{A})$ versus $1 /[$ monosaccharide or aminoglycoside antibiotics) was utilized to calculate the association constant. As summarized in Table 1, the binding constant $\mathrm{K}_{\mathrm{a}}$ were obtained from the linear fitted data to the Benesi-Hildebrand equation. 

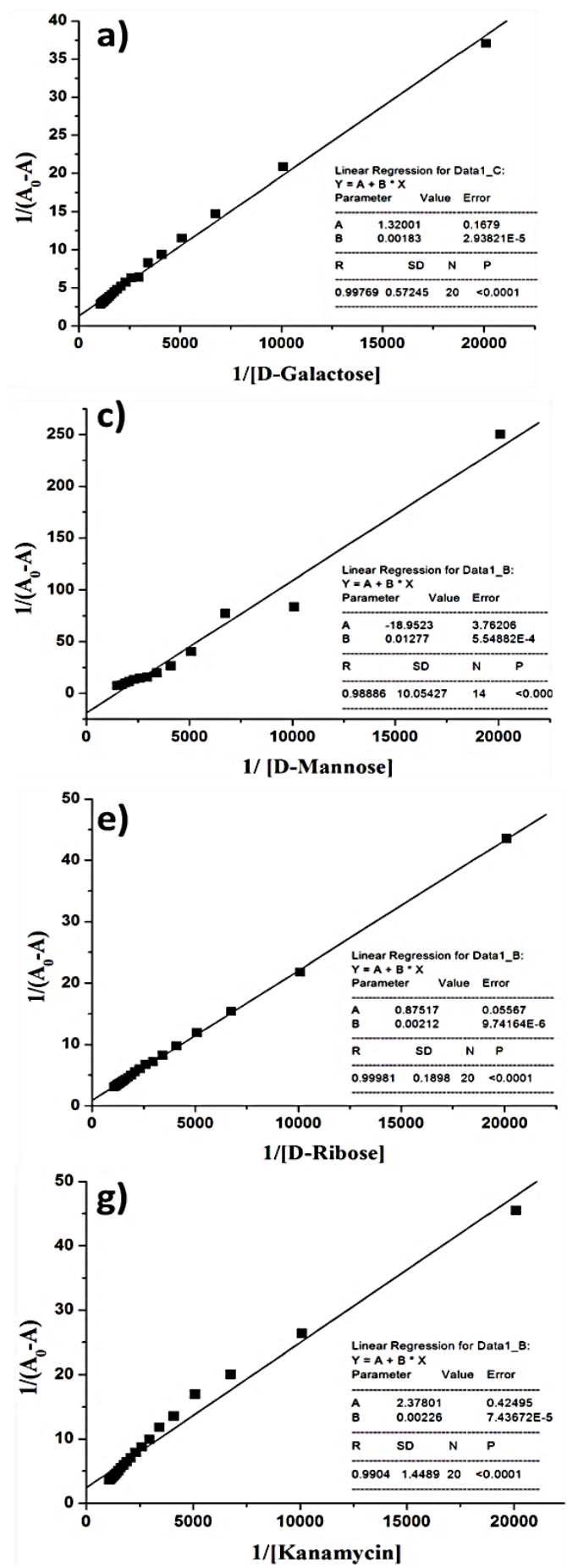
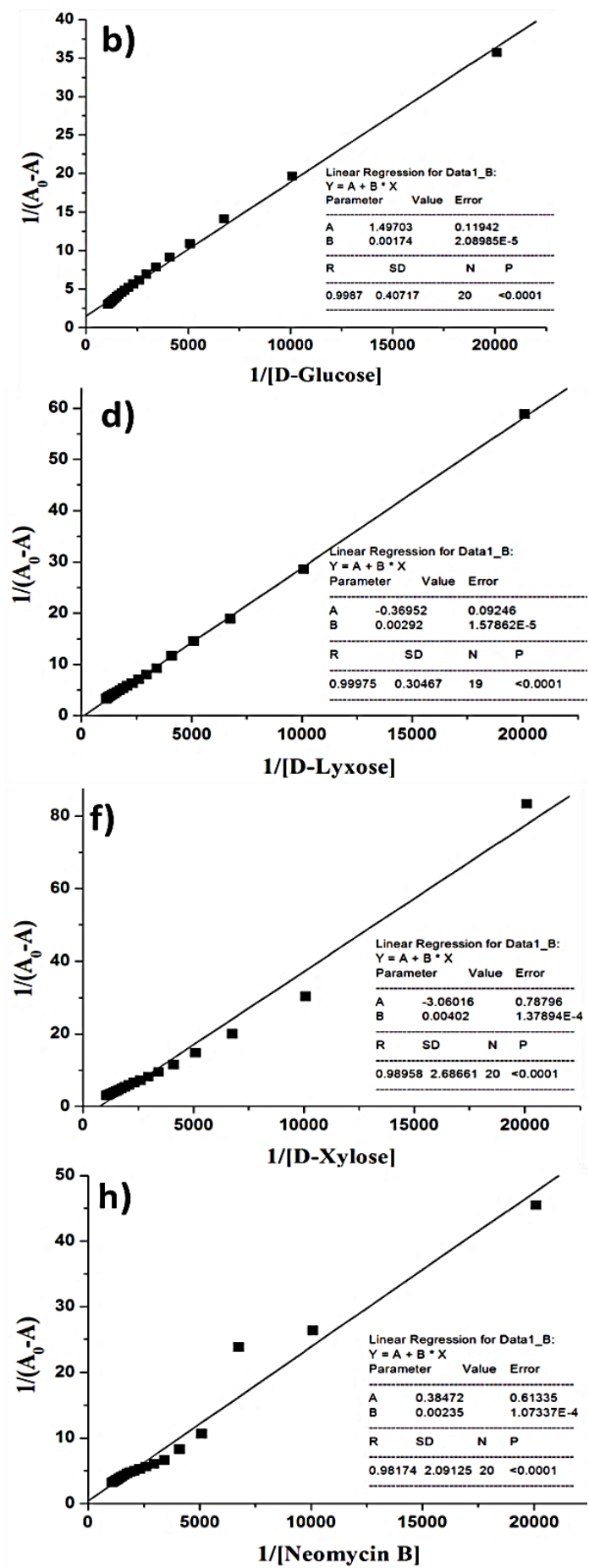

Fig. 4 Benesi-Hilderbrand plot of bolaamphiphile NDI 1 with D- form of sugars as: a) galactose, b) glucose, c) mannose, d) lyxose, e) ribose, f) xylose as well as antibiotics: g) kanamycin and h) neomycin. 
Table 1: Binding constant of bolaamphiphile NDI 1 with saccharides and aminoglycoside antibiotics in $\mathrm{H}_{2} \mathrm{O}$.

\begin{tabular}{ccc}
\hline Sr. No. & $\begin{array}{c}\text { Carbohydrates/Aminoglycoside } \\
\text { antibiotics }\end{array}$ & Association Constant $\left(\mathbf{K}_{\mathbf{a}}\right)$ \\
\hline 1 & D-galactose & $4.13 \times 10^{-2} \mathrm{M}$ \\
2 & D-glucose & $3.85 \times 10^{-2} \mathrm{M}$ \\
3 & D-mannose & $4.39 \times 10 \mathrm{M}$ \\
4 & D-lyxose & $9.26 \times 10^{-2} \mathrm{M}$ \\
5 & D-ribose & $5.39 \times 10^{-2} \mathrm{M}$ \\
6 & D-xylose & $8.12 \times 10^{-2} \mathrm{M}$ \\
7 & kanamycin & $1.86 \times 10^{-2} \mathrm{M}$ \\
8 & neomycin A & $1.10 \times 10^{-3} \mathrm{M}$ \\
\hline
\end{tabular}

\subsection{Fluorescence spectroscopy}

The fluorescence emission spectroscopic technique was utilized to study the binding interactions of bolaamphiphile NDI 1 with monosaccharides at $\mathrm{pH} 9$ in $\mathrm{H}_{2} \mathrm{O}$. The fluorescence emission spectroscopy results of the bolaamphiphile NDI 1 and their non-covalent interaction with different carbohydrates is illustrated in Fig. 5a-f. The molecular receptor NDI $1\left(1 \times 10^{-5}\right.$ M) at $\mathrm{pH} 9$ in aqueous media, displays the two strong emission peaks at $414 \mathrm{~nm}$ and $547 \mathrm{~nm}$ $\left(\lambda_{\mathrm{ex}}=384 \mathrm{~nm}\right)$. This is attributed to the monomeric form of the bolaamphiphile NDI-1. At first emission spectral changes of NDI 1 was recorded with the addition of various monosaccharides (20 equiv.). The addition of various monosaccharides to a solution of bolaamphiphile NDI 1 show significant changes in fluorescence emission intensity (Fig. 5a-f) was resulted. As illustrated in Fig. 5a, with the addition of D-galactose to NDI 1, the emission peak at $414 \mathrm{~nm}$ increases significantly, whereas, the peak at $547 \mathrm{~nm}$ decreases. This changes in fluorescence peak intensity resulted into isosbestic point at $525 \mathrm{~nm}$, indicating the formation of complex. 
Similar trend of emission intensity changes was observed for NDI 1 with the addition of other sugars (Fig. 5b-f). Such change in emission spectra is attributed to the complex formation between NDI 1 and tested monosaccharides via non-covalent H-bonding interactions.

Furthermore, to generalise the molecular recognition of NDI 1, we tested kanamycin and neomycin aminoglycosides. As illustrated in Fig. $6 a$ and 6b, with the addition of kanamycin and neomycin, respectively, NDI 1 display the change in emission peak, at $414 \mathrm{~nm}$ increase in intensity and at 547 $\mathrm{nm}$ decrease in peak intensity was observed. Herein, as shown in Fig. 6a and Fig 6b, at $525 \mathrm{~nm}$ isosbestic point formation was observed. This suggests that bolaamphiphile NDI 1 interacts with kanamycin and neomycin via complex formation. This complexation is attributed to the noncovalent hydrogen bonding formation. Thus, the similar trend for molecular recognition of monosaccharides and aminoglycoside antibiotics was observed. 

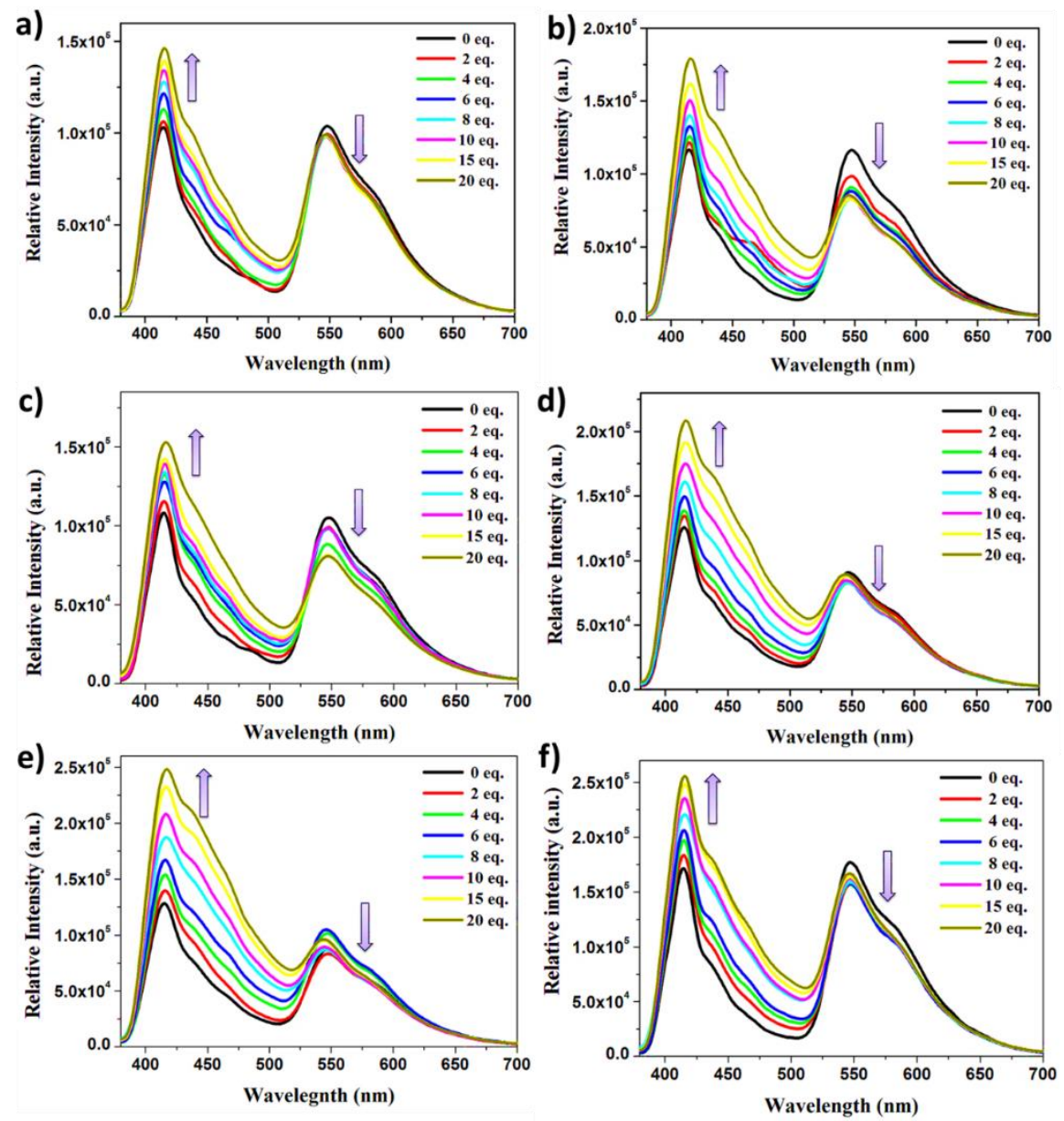

Fig 5 Fluorescence of NDI $1\left(c=1 \times 10^{-5} \mathrm{M}\right)$ with addition of various saccharides in the Dform such as: a) galactose, b) glucose, c) mannose, d) lyxose, e) ribose and f) xylose (0-20 equiv., $\left.1 \times 10^{-2} \mathrm{M}\right)$ ) at $\mathrm{pH} 9$ in $\mathrm{H}_{2} \mathrm{O}$.
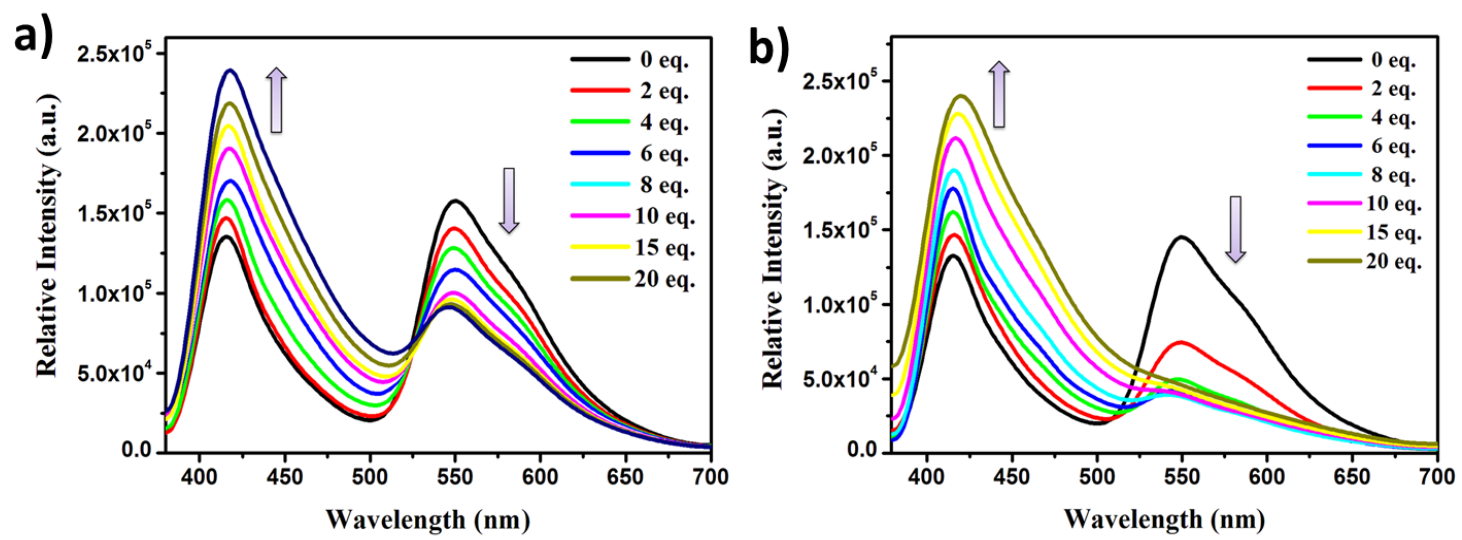

Fig. 6 Fluorescence of bolaamphiphile NDI $1\left(1 \times 10^{-5} \mathrm{M}\right)$ upon excitation at $\left.\lambda_{e x}=380 \mathrm{~nm}\right)$ with the addition of a) kanamycin $\left(0-20\right.$ equiv., $\left.1 \times 10^{-2} \mathrm{M}\right)$ and $\left.\mathrm{b}\right)$ neomycin $(0-20$ equiv., $1 \mathrm{x}$ $\left.10^{-2} \mathrm{M}\right)$ ) at $\mathrm{pH} 9$ in $\mathrm{H}_{2} \mathrm{O}$. 
In Fig 7, we demonstrated that the plausible binding mode of phosphonic appended bolaamphiphile NDI 1 with monosachharides/aminoglycosides. Herein, we presume that at $\mathrm{pH} 9$, the fully deprotonated phosphonic functional group interacts with monosachharides/aminoglycosides through non-covalent hydrogen bonding. The change in UV-vis and fluorescence emission spectra was observed due to intermolecular $\pi-\pi$ interactions of core of NDIs.
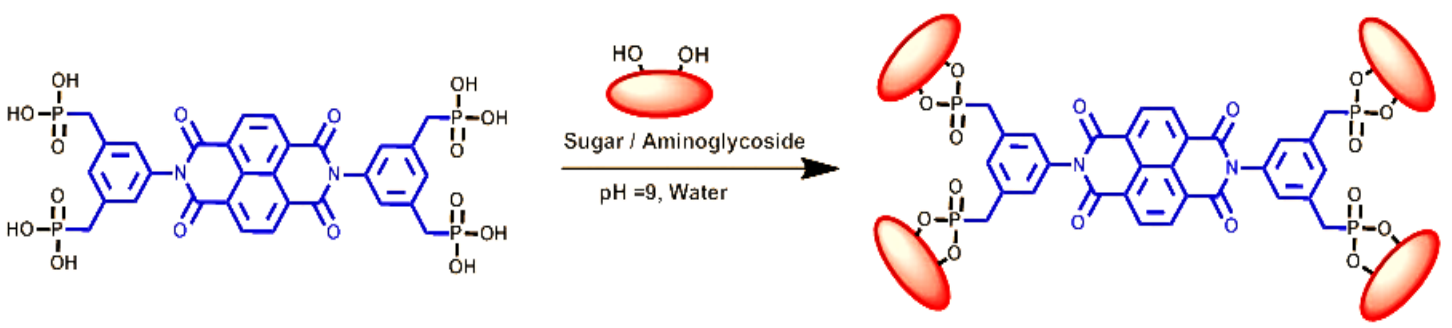

Fig. 7 Schematic presentation displaying the plausible binding mode between bolaamphiphile NDI 1 with monosachharides/aminoglycosides.

\section{Conclusion}

In summary, we developed phosphonic acid appended NDI 1 bolaamphiphile for molecular recognition of monosachharides of the D- form such as galactose, glucose, fructose, lyxose, ribose, and xylose and aminoglycoside antibiotics e.g. kanamycin and neomycin with association constant ranging from $10^{-2} \mathrm{M}$ to $10^{-3} \mathrm{M}$. The binding between fully deprotonated phosphonic acid with $-\mathrm{OH}$ and/or $-\mathrm{NH} 2$ is attributed to the non-covalent H-bonding. We believe that NDI 1 receptor with phosphonic head group undergoes molecular recognition for monosachharides/aminoglycosides could be valuable tools to recognise the specific molecular entities and opens new avenue in the field of research.

\section{Declaration of Competing Interest}

The authors declare that they have no known competing financial interest or personal relationships that could have appeared to influence the work reported in this paper.

\section{CRediT role(s) Authorship contribution statement}


Kamalakar P. Nandre: Methodology; manuscript corrections; Sidhanath V. Bhosale: PI, conceptualization, manuscript writing \& corrections.

\section{Acknowledgements}

S.V.B. (IICT) are grateful to financial support from BRNS under the project No.: 58/14/01/2020-BRNS/37047 and the Director, CSIR-IICT (MS No. IICT/Pubs./2021/160).

\section{References}

[1] K. S. Lau, J. W. Dennis, N-Glycans in cancer progression, Glycobiology 18 (2008) 750760.

[2] E. I. Buzas, B. Gyorgy, M. Pasztoi, I. Jelinek, A. Falus, H. Gabius, Carbohydrate recognition systems in autoimmunity, Autoimmunity 39 (2006) 691-704.

[3] H. E. Murrey, L. C. Hsieh-Wilson, The chemical neurobiology of carbohydrates, Chem. Rev. 108 (2008) 1708-1731.

[4] (a) G. Reuter, H-J. Gabius, Eukaryotic glycosylation-whim of nature or multipurpose tool? Cell Mol Life Sci 55 (1999) 368-422; (b) R. N. Fedoak, M. D. Gershon and M. Field, Induction of intestinal glucose carriers in streptozocin-treated chronically diabetic rats, Gasteroenterology 96 (1989) 37-44; (c) T. Yamamoto, Y. Seino, H. Fukumoto, G. Koh, H. Yano, N. Inagaki, Y.Yamada, K. Inoue, T. Manabe and H. Imura, Overexpression of facilitative glucose transporter genes in human cancer, Biochem. Biophys. Res.Commun. 170 (1990) 223-230.

[5] C. Zhang and K. S. Suslick, Syntheses of boronic-acid-appended metalloporphyrins as potential colorimetric sensors for sugars and carbohydrates, J. Porphyrins Phthalocyanines 9 (2005) 659-666.

[6] W.-K Oh, Y. S. Jeong, K. J. Lee, J. Jang, Fluorescent boronic acid-modified polymer nanoparticles for enantioselective monosaccharide detection, Anal. Methods 4 (2012) 913-918. 
[7] J. Zhai, T. Pan, J. Zhu, Y. Xu, J. Chen, Y. Xie, Y. Qin, Boronic acid functionalized boron dipyrromethene fluorescent probes: preparation, characterization, and saccharides sensing applications, Anal. Chem. 84 (2012) 10214-10220.

[8] M-S. Steiner, A. Duerkop, O. S. Wolfbeis, Optical methods for sensing glucose, Chem. Soc. Rev. 40 (2011) 4805-4839.

[9] R. Badugu, J. R. Lakowicza, C. D. Geddes, Boronic acid fluorescent sensors for monosaccharide signaling based on the 6-methoxyquinolinium heterocyclic nucleus: progress toward noninvasive and continuous glucose monitoring, Bio. Med. Chem. 13 (2005) 113-119.

[10] J. R. Askim, M. Mahmoudi, K. S. Suslick, Optical sensor arrays for chemical sensing: the optoelectronic nose, Chem. Soc. Rev. 42 (2013) 8649-8682.

[11] J. Zhao, T. D. James, Chemoselective and enantioselective fluorescent recognition of sugar alcohols by a bisboronic acid receptor, J. Mater. Chem. 15 (2005) 2896-2901.

[12] J. Zheng, W. Qiao, X. Wan, J. P. Gao, Z. Y. Wang, Near-infrared electrochromic and chiroptical switching materials: design, synthesis, and characterization of chiral organogels containing stacked naphthalene diimide chromophores, Chem. Mater. 20 (2008) 6163-6168.

[13] G. Vancoillie, S. Pelz, E. Holder, R. Hoogenboom, Polym. Direct nitroxide mediated (co)polymerization of 4-vinylphenylboronic acid as route towards sugar sensors, Chem. 3 (2012)1726-1729.

[14] A. S. Brown, H. -C. Wang, P. Iqbal, J. A. Preece, Y. Long, J. S. Fossey, T. D. James, P. M. Mendes, Glucose selective Surface Plasmon Resonance-based bis-boronic acid sensor, Analyst 138 (2013) 7140-7145.

[15] V. Tharmaraj, K. Pitchumani, D-Glucose sensing by (E)-(4-((pyren-1-ylmethylene) amino)phenyl) boronic acidvia a photoinduced electron transfer (PET) mechanism, RSC 
Adv. 3 (2013) 11566-11570.

[16] (a) K. K. Ghosh, E. Yap, H. Kim, J. -S. Lee, Y. -T. Chang, A colorimetric pH indicators and boronic acids ensemble array for quantitative sugar analysis, Chem. Commun. 47 (2011) 4001-4003; (b) T. D. James, P. Linnane, S. Shinkai, Fluorescent saccharide receptors: a sweet solution to the design, assembly and evaluation of boronic acid derived PET sensors, Chem. Commun. (1996) 281-288.

[17] G. Springsteen, B. Wang, A detailed examination of boronic acid-diol complexation, Tetrahedron Lett. 2002, 58, 5291-5300.

[18] M. D. Phillips, T. M. Fyles, N. P. Barwell, T. D. James, Carbohydrate sensing using a fluorescent molecular tweezer, Chem. Commun. (2009) 6557-6559.

[19] R. U. Lemieux, Rhône-Poulenc lecture. The origin of the specificity in the recognition of oligosaccharides by proteins, Chem. Soc. Rev. 1989, 18, 347-374.

[20] S. Craig, Synthesis and evaluation of aryl boronic acids as fluorescent artificial receptors for biological carbohydrates, Bioorg. Chem. 40 (2012) 137-142.

[21] S. R. Inglis, M. Strieker, A. M. Rydzik, A. Dessen, C. J. Schofield, A boronic-acid-based probe for fluorescence polarization assays with penicillin binding proteins and $\beta$ lactamases, Anal. Biochem. 420 (2012) 41-47.

[22] (a) B. Lee, S. Chen, C. Heinis, R. Scopelliti, K. Severin, Pattern-based sensing of peptides and aminoglycosides with a single molecular probe, Org. Lett. 15 (2013) 3456-3459; (b) R. W. Jadhav, M. Al Kobaisi, L. A. Jones, A. Vinu, S. V. Bhosale, The supramolecular self-assembly of aminoglycoside antibiotics and their applications, ChemistryOpen 8 (2019) 1154-1166.

[23] (a) V. Kral, O. Rusin, F. P. Schmidtchen, Novel porphyrin-cryptand cyclic systems: receptors for saccharide recognition in water, Org. Lett. 3 (2001) 873- 876; (b) R. D. Hubbard, S. R. Horner, B. L. Miller, Highly substituted ter-cyclopentanes as receptors for 
lipid A, J. Am. Chem. Soc. 123 (2001) , 5810-5811; (c) R. Yanagihara, Y. Aoyama, Enhanced sugar-binding ability of deprotonated calix[4]resorcarene in water: Balance of CH- $\pi$ interaction and hydrophobic effect, Tetrahedron. Lett. 35 (1994) 9725-9728

[24] (a) V. Kral, O. Rusin, J. Charvatova, P. Anzenbacher, J. Fogl, Porphyrin phosphonates: novel anionic receptors for saccharide recognition, Tetrahedron Lett. 41 (2000) 10147-10151; (b) C. M. Renney, G. Fukuhara, Y. Inoue, A. P. Davis, Binding or aggregation? Hazards of interpretation in studies of molecular recognition by porphyrins in water, Chem. Commun. 51 (2015) 9551-9554.

[25] G. Das, A. D. Hamilton, Carbohydrate recognition: Enantioselective spirobifluorene diphosphonate receptors, Tetrahedron Lett. 38 (1997) 3675-3678.

[26] U. Neidlein, F. Diederich, Selective complexation of disaccharides by a novel $D_{2}$ symmetrical receptor in protic solvent mixtures, Chem. Commun. (1996) 1493-1494.

[27] G. Das, A. D. Hamilton, Molecular recognition of carbohydrates: strong binding of alkyl glycosides by phosphonate derivatives, J. Am. Chem. Soc. 116 (1994) 11139-11140.

[28] S. Anderson, U. Neidlein, V. Gramlich, F. Diederich, New family of chiral binaphthylderived cyclophane receptors: complexation of pyranosides, Angew.Chem., Int. Ed. Engl. 34 (1995) 1596-1600.

[29] S. T. Rao, M. Sundaralingam, Stereochemistry of nucleic acids and their constituents. V. Crystal and molecular structure of a hydrated monosodium inosine 5'-phosphate. Commonly occurring unusual nucleotide in the anticodons of tRNA, J. Am. Chem. Soc. 91 (1969) 1210-1217.

[30] H. Pelmore, G. Eaton, M. C. Symons, Binding of sugars to DNA. An NMR study of Dfructose, J. Chem. SOC., Perkin Trans.2 1992, 149-150.

[31] (a) K. P Nandre, S. V. Bhosale, K. V. S. Rama Krishna, A. Gupta, S. V. Bhosale, A phosphonic acid appended naphthalene diimide motif for self-assembly into tunable 
nanostructures through molecular recognition with arginine in water, Chem. Commun. 49 (2013) 5444-5446; (b) R. S. Bhosale, M. Al. Kobaisi, S. V. Bhosale, S. Bhargava, S. V. Bhosale, Flower-like supramolecular self-assembly of phosphonic acid appended naphthalene diimide and melamine, Sci. Rep. 5 (2015) 14609.

[32] (a) C. Röger, F. Würthner, Core-tetrasubstituted naphthalene diimides: synthesis, optical properties, and redox characteristics, J. Org. Chem. 72 (2007) 8070-8075; (b) M. Al Kobaisi, S.V. Bhosale, K. Latham, A.M. Raynor, S. V. Bhosale, Functional naphthalene diimides: synthesis, properties, and applications, Chem. Rev. 116 (2016) 11685-11796. 